\title{
METHODOLOGICAL GUIDELINES ON THE LEARNING AND PERFECTING OF SELF-DEFENSE TECHNIQUES IN THE FIGHTERS' TRAINING
}

\author{
Robert STĂNCIULESCU \\ "Nicolae Bălcescu” Land Forces Academy, Sibiu, Romania \\ rstanciulescu@armyacademy.ro
}

Elvira BELDIMAN

Bucharest Bar Association, Romania avoelvira@yahoo.co.uk

\begin{abstract}
In terms of forming and training the fighters, the modern armies have delineated well-defined instructive horizons, the development of the physical potential, characterized by the increase of the parameters of manifestation of the basic motor qualities as well as of the motor skills and applicative skills specific to carrying out the combat actions being very well harmonized with the development of intellectual, psychological, moral and specialist competencies. The maximization of the capacity of effort to meet the intensive and long-lasting demands as well as the improvement of the fighting skills specific to the modern combat area represent a permanent concern of the specialists in the field, who amplify the training process in an activity based on the most complex and efficient training techniques. The paper presents the techniques, methods and means for optimizing the training in the selfdefense combat, in order to ensure a rich bag of scientific information necessary in accomplishing the objectives for the training of the fighters.
\end{abstract}

KEYWORDS: self-defense, combat, potential, effort, technique

\section{Introduction}

The level of development of the physical exercise capacity is essential in the process of training a fighter able to cope with the fatigue conditions that combat requires, and with the stress generated by uncertainty, fear, panic or surprise as well. Developing the combative spirit, courage and group cohesion, the process of development and optimization of the physical potential ensures and maximizes the volitional-moral components of the fighter, implicitly increasing the power of survival in unfavorable combat conditions. Enhancing the ability to quickly act by using the weaponry and equipment in the conditions of combat, while stationary or moving, the training and development of resistance to long-distance physical exercise, moving on land or on vehicles, under difficult terrain and climate conditions, and increasing the ability to withstand static and reduced mobility positions for a long time, developing physical strength when boarding on and disembarking materials from vehicles and 
craft, increasing the reaction speed and executing neuro-motor coordination in handling the armament and combat technique, increasing resistance to longlasting efforts, the development of strength and force specific to conducting close combat are just some of the objectives of a well-organized and developed training process that can bring vital benefits.

Among the sport disciplines that are part of the training process, self-defense is an extremely complex component because it incorporates elements and methods of fighting specific to established sports disciplines, such as judo, jiu-jitsu, taekwono, kiokusin or simply body fighting with the individual weapon provided.

The variety of situations in which a fighter has to apply such techniques requires a well-directed training process that provides, besides spontaneity and safety, a solid base of skills and aptitudes that can be adapted to achieve success in combat. That is why the preoccupations for the harmonization of the specific techniques of different sports with the concrete situations that combat requires is a permanent concern of the specialists in the field.

\section{Self-defense Techniques and Methodological Guidelines}

The content of self-defense techniques is of great complexity and diversity at the same time as it has taken over the most effective defense and response from a large number of combat sports, and represents a complex system of skills and abilities capable of providing effective solutions in conflict situations. Mastering a rich system of skills specific to this type of combat involves, besides the knowledge of the specific procedures of various sport disciplines, a vast process of psychological and physical training that will provide the psychological potential necessary for the successful application of the most effective combat procedures (Stănciulescu, 2016). There are certainly no rules for the combatants in the battlefield, however the training process supposes adherence to some training principles that allow the acquisition and perfection of the techniques at optimal parameters.

\subsection{Physical Training in Self-Defense}

This type of training provides the necessary energy support for carrying out the fight, but also the basis of the correct acquisition of the skills and motor aptitudes characteristic of the various sport disciplines, the quickness and the correctness in the learning of the technical procedures largely depending on its level of development. First of all, it involves the increase of the functional capacity of the body, as well as the development to different extents of the motor skills required in self-defense combat. The rhythm changes, the interplay of effort, the continuous alternation of the forms of movement and the intensity of the specific effort imply the choice of a training system that responds to these characteristics, the physiological effects manifested in the organs and the systems of the body being reflected in the maximization of the technical elements (Hantău, 2005).

Speed, as a basic motor quality in self-defense combat, can play an essential role in this type of combat, because in a real confrontation the one who is the first is the winner, most of the time. In terms of importance, speed ranks first among the motor qualities, followed by coordination of movements, specific strength and resistance. It has four forms of manifestation, namely: the reaction speed, representing the reaction time or the latent period of the elementary motor reaction; the speed of execution of movements; the specific repetition speed, determinant in carrying out the movements and the motion speed that expresses the integral speed. We can also talk about the speed in a force mode and the speed in a resistance mode, the latter characterizing the physical training 
specific to self-defense. In achieving the maximum efficiency of a technical process, the determinant role is held by its reaction speed and the speed of execution because they determine the start and realization of the actions of attack, counterattack, defense, or combinations of these, but in a real situation all the manifestations presented are essential for efficiency.

Methodical guidelines on developing the speed specific to self-defense

The main form of speed development is to perform efforts at a maximum speed, with short and rapid contractions primarily at the level of the muscular groups involved in the technical process or element, but also throughout the whole body. Therefore the intensity being maximum, the specialists in the field concluded that, in order to be effective, the recommended efforts should not exceed 10 seconds and the rest periods of the body must be at least 40 seconds, rest being of the active type, because it ensures the body to return to the state of maximum excitability in a faster and more efficient way. The physical exercises to be used in the training process must be similar to those performed in the real battle and in the most diversified conditions. Here are the main methods of speed development in selfdefense (Deliu, 2016):

- the method of repeating the techniques under relaxed conditions, which are executed with maximum tempo and normal rest breaks, but with slow, slender partners that help to execute the procedure;

- the signal-based method, in which for efficiency it is recommended to alternate the intensity of the signals, alternate the time at which the signals are given, the alternation of the velocity in which the signal response is executed (from maximum executions to slow, then to super maximum, etc.), as well as the frequent change of the position from which the reaction takes place;
- the technique of repeating the procedures under difficult conditions, which are executed with partners who provide light resistance, with heavier partners or executed with eyes closed and in the most diversified conditions;

- the method of executing attentionplaying games characterized by combat and competition, that is performed in short intervals and with maximum emotional motivation.

The training sessions for speed development are scheduled in the first part of the lesson, and only after previous easy training. It is advisable to stop the work at the first signs of fatigue and the breaks between the repetitions must be at least eight times longer than the intensive work periods.

Strength is a motor quality with major effects in self-defense. Although it ranks on the third place in terms of importance for self-defense, the specialists' concerns for its development are increasingly greater, since in combination with speed, it ensures the execution of the tactical actions at the highest performance standards.

There are a large number of classifications of strength as a motor quality, but in self- defense there are three types of strength that characterize this discipline:

- the maximum strength, which is the greatest force the neuromuscular system produces in a voluntary contraction;

- the strength/speed that is characterized by the ability of the neuromuscular system to overcome resistance with the highest possible contraction speed;

- the resistant strength, which is the ability that allows the body to resist fatigue by a performance in which strength is combined with duration.

Methodical guidelines on developing strength in self-defense

The methodical ways for the development of strength are multiple and they can be adapted to the particularities of 
sport disciplines. In our case the most important procedures are:

- the process of performing movements involving intense and rapid muscle contractions. This procedure does not refer to the increase in muscle mass but to the ability of the muscle to contract in the shortest time, being used to develop strength in a speed mode;

- the weight lifter method is another method by which the development of maximum strength is achieved. The reference element in this method is the progressive increase in load;

- POWER-TRAINING is a method used to develop strength in a speed mode. In this method the main elements refer to (Mitra \& Mogos, 1980):

- the load size;

- enhancing the number of repetitions;

- increasing the execution speed;

- procedure in the circuit - aims at developing the main muscle groups. In this method it is recommended:

- the complexity of the exercises should gradually increase;

- the difficulty should not be big.

During the training, it is necessary to observe the following:

- performing the body preparation sequence for effort at maximum parameters;

- to have adequate breaks to restore the body's physical exercise capacity;

- to carry out careful and thorough coordination of the volume-intensity relationship.

During the training session, special attention will be given to restoring the body condition after physical effort, in strict accordance with the established objectives. Skill has a special role in self-defense combat, being second in terms of its importance as a motric quality. Through its manifestations, it is represented by balance, spatio-temporal orientation, flexibility, amplitude or muscle relaxation (Tudor, 1999).
Methodical guidelines on developing the skill specific to self-defense

The methodical procedures for the development of skill in self-defense are:

- conducting motor actions under constant conditions;

- carrying out motor actions and acts in variable conditions;

- carrying out motor actions and acts in difficult conditions;

- ballistic techniques representing the execution of repeated dynamic contractions of motor muscles;

- muscle stretch techniques.

For efficiency, it is necessary to follow the following guidelines:

- the development of the skill is achieved at the beginning of the physical education lesson (in the first part of the training sequence) or during the preparation of the body for effort through specific exercises in the conditions of a rested body; observing sufficiently large rest intervals to allow the body to cope with the imposed demands;

- it should be taken into account that the workload should be small and the exercises used as many as possible, more difficult and relaxing at the same time;

- the developmental exercises of the skill should be scheduled in the conditions of a rested body and should contain exercises with an increased level of difficulty;

- at the same time, the methodical procedures of developing the skill will be influenced by the degree of difficulty of the exercises used, the precision in space, the execution speed, the motor strain and the synchronization of the movements.

Resistance is a motric quality with special implications in acquiring and improving the self-defense techniques, as it allows the body to cope with fatigue in the great efforts that combat demands. 
In self defense the main methods of resistance development are:

- the method of repeating the efforts with uniform intensities in which the restoration of the oxygen substrate necessary to the body is done during the course of the activity. It is characterized by constant intensity and volume variation;

- the method of repeating the efforts with the change of intensity, in which the anaerobic type of effort predominates, and the intensity increases progressively or variably from one motor action to another;

- the method of applying variable efforts that is characterized by both volume and intensity variation. Besides being able to be used in any training conditions, the advantage of this type of training improves the cardiorespiratory function and is considered a procedure with a high efficiency in the development of the qualities of will and psychological resistance of fighters.

It is advisable to observe the following requirements during training:

- observing the times for work and rest;

- observing the frequency of training exercises for developing strength;

- the development of resistance should be carried out on complex motor actions both in attack and defense;

- the training sessions should aim at developing both the aerobic resistance in the first phase and the anaerobic resistance;

- the training sessions will take place so as to ensure the unpredictable situation, which is characteristic of self-defense.

\subsection{The Technical Training Itself in}

\section{Self-Defense Combat}

In self-defense combat, usually the most effective technical elements, procedures or combinations of technical procedures are used in most combat sports. Of great importance in acquiring and perfecting the technique are a series of knowledge and skills that must be known and learned before acquiring the techniques of attack, counterattack or defense.

The battlefield positions used in selfdefense combat must be known by the fighters because they have peculiarities that can offer advantages or disadvantages and can ensure the success of the combat, as follows:

- the front position, considered by many to be the ideal position, implies a halfflexion of the legs that are parallel and on the same line, as far from each other as the shoulder width and the weight equidistant on both legs. The arms are bent with the elbows protecting the floating ribs and the fists are tight and protect the chin. This position ensures a very good balance, possibilities of attack on both sides, safety and control over the body;

- the semi-frontal position where the body is facing forward with a 45 - degree inclination towards the enemy, the leg and the non-dominant arm in front. It is a position of both attack and protection;

- the lateral position represents an ideal position for defense as it minimizes the opponent's possibilities to attack the vital points of the body, but requires effort to obtain an effective counterattack position;

- the position of the samurai recommended in the case of the ground combat because it offers increased mobility, good stability and can provide freedom of action for the legs. Learning and perfecting the battle positions can be done both at the beginning of the training sessions and throughout them through multiple repetitions, changes of position at the command or on one' $s$ own initiative, as well as within the combat with a partner.

In the case of training with partners, the combat distances demand knowledge on the partners' peculiarities, offering advantages or disadvantages: 
- the long combat distance is that distance where the opponents study each other and perform easy movements in order to identify the vulnerabilities and make the decision;

- the optimal combat distance involves the possibility of carrying out the attack, counterattack and, of course, defense with both arms and other parts of them. It is preferred by those who possess a big arm length and by those with well-developed motor skills, because it involves the real combat.

- the fire distance is the distance in which the opponents are in contact, any form of attack being possible.

The movements in self-defense can be done through normal steps, added steps, circular steps or roll-overs. Of great importance in the training process is also the psychic concentration that ensures a good combat condition in the unpredictable and surprise situations that occur during combat.

The strikes can be of attack, counterattack or defense and represent the contact with the different parts of the opponent's body. They can be performed with the arms or with their different parts (fist, forearm, elbow, the edge of the hand, fingers, etc.), with the legs (knee, shin, heel, etc), with the head or other firm parts of the body. The blows can be: direct, circular, top-bottom, bottom-top, roll-overs, or any other type of blow that is suited in the course of the combat. They represent advantages and disadvantages depending on the level of the mastery of the technique and the level of development of the motor qualities:

- the circular strikes are much stronger than the direct ones;

- the rebounds provide an increased strike force - kicks have the advantage of the strike force, as well as of the distance to the opponent, but are much slower.

Locks are designed to stop the opponent's strikes and create the conditions for launching the counterattack. They can be executed with the arms and legs or with their different parts, being effective due to the shock absorption caused by the blows of the opponent.

Shirks are means of defense by avoiding the opponent' s strikes; they can be lateral, circular, to the lower part, to the back, or in any direction which provides this possibility.

Parries are combinations of strikes and blocks, representing ways to reduce the force of the blows and they can be performed with the arms and legs or with parts of them.

Projections are ways of throwing the opponent to the ground and they are done with the arms and legs, as well as with their different parts by coordinating them according to the situations created (Hantău, 1996).

For efficiency, projections can be continued with strangulations, sprains, or immobilizations that can permanently take the opponent out of combat.

Methodical guidelines for learning and reinforcing the technical procedures

For a proper acquisition of selfdefense techniques and for avoiding injuries in the training process, it is advisable to observe certain rules:

- preparing the body for effort in close harmony with the objectives and the complexity of the lessons;

- creating and maintaining a climate of order and irreproachable discipline;

- observing the principles of learning, from simple to complex, from easy to difficult, from known to unknown;

- the demonstration will be accompanied by explanations and exemplifications;

- the dynamic stereotype of the movement that has to be learned will be acquired before the execution;

- observing the algorithm as an essential working method for the complex structures;

- the use of intuitive means in the training process, such as charts, power-point presentations, films, executions by trained subjects, etc; 
- elimination of mistakes during the training process;

- in the learning phase, the pairs will be achieved by combinations between beginners and advanced trainees;

- combinations of procedures will be learned only after the correct acquisition of the individual technical elements and procedures;

- conducting the training sessions in a competitive form, done progressively will certainly have an important role;

- the fighters' stimulation throughout the training process ensures a faster and more appropriate assimilation of the combat technique.

\section{Conclusions}

With the aim of forming, strengthening and refining the close combat skills with applicability to the diversion and counterdiversion actions, as well as in the missions where the individual firefighting equipment cannot be used, physical self-defense largely contributes to the formation of fighters with a physical and psychological potential, allowing them to respond to the comlexity of the specific demands of the modern battlefield. Due to the special effects they have on the body, the means and methods of training used in self-defense combat are useful and effective ways of achieving the formative objectives, constituting a permanent challenge for the specialists in the field with a view to maximizing performance in the training of fighters.

\section{REFERENCES}

Deliu, D. (2016). Tehnici de autoapărare. Bucureşti: Editura Discobolul.

Hantău, I. (1996). Manual de judo. Bucureşti: Editura Didactică şi Pedagogică.

Hantău, I. (2005). Teoria şi metodica judoului. Bucureşti: Universitatea Naţională de Educație Fizică și Sport.

Mitra, Ghe., \& Mogoș, A. (1980). Metodica educaţiei fizice şcolare. Bucureşti: Editura Sport-Turism.

Stănciulescu, R. (2016). Capacitatea Motrică, Fundamente teoretice şi metodice. Sibiu: Editura Academiei Forţelor Terestre „Nicolae Bălcescu”.

Tudor, V. (1999). Capacităţile condiţionale, coordinative şi intermediare - componente ale capacităţilor motrice. Bucureşti: Editura Coresi. 